\title{
AKIBAT HUKUM YANG DITIMBULKAN MENGENAI CRYPTOCURRENCY SEBAGAI ALAT PEMBAYARAN DI INDONESIA
}

\author{
Haruli Dwicaksana \\ E-mail: harulidwicaksono@gmail.com \\ Mahasiswa Fakultas Hukum Universitas Sebelas Maret \\ Pujiyono \\ E-mail: pujifhuns@gmail.com \\ Dosen Fakultas Hukum Universitas Sebelas Maret
}

\begin{abstract}
This article aims to know the use of cryptocurrency can replace conventional money as a means of payment in Indonesia. This article belongs to the type of normative legal research that is prescriptive to produce a new concept in resolving the problems faced by supported by a legal approach and a case approach. The data used is secondary data with primary binding and fundamental material. Data collection techniques using library studies. The data analysis technique used by the authors is a silogism analysis. The results showed that cryptocurrencies are difficult to substitute for conventional currency use as a means of payment in Indonesia because there is no centralized authority governing as well as the value of a relatively unstable cryptocurrency from Conventional currency that has been circulating in Indonesia is the rupiah, it is difficult to use cryptocurrency as a means of payment at the least level of Use daily.
\end{abstract}

Keywords: Payment Tools; Paymeny Systems; Conventional Currency; Cryptocurrency.

\begin{abstract}
Abstrak
Artikel ini bertujuan untuk mengetahui penggunaan cryptocurrency dapat menggantikan uang konvensional sebagai alat pembayaran di Indonesia. Artikel ini termasuk ke dalam jenis penelitian hukum normatif yang bersifat preskriptif untuk menghasilkan konsep baru dalam menyelesaikan permasalahan yang dihadapi, didukung dengan pendekatan undang-undang dan pendekatan kasus. Data yang digunakan merupakan data sekunder dengan bahan hukum primer yang sifatnya mengikat dan mendasar. Teknik pengumpulan data menggunakan studi kepustakaan. Teknik analisis data yang digunakan penulis merupakan analisis silogisme. Hasil penelitian menunjukkan bahwa cryptocurrency sulit untuk menggantikan kegunaan mata uang konvensional sebagai alat pembayaran di Indonesia karena tidak ada otoritas terpusat yang mengatur serta nilai dari cryptocurrency yang relatif tidak stabil dari mata uang konvensional yang sudah beredar di Indonesia yaitu rupiah, maka sulit untuk menggunakan cryptocurrency sebagai alat pembayaran di tingkat paling kecil yaitu penggunaan seharihari.
\end{abstract}

Kata Kunci: Alat Pembayaran; Sistem Pembayaran; Uang Konvensional; Cryptocurrency.

\section{A. Pendahuluan}

Berkembangnya perdagangan dunia yang kian hari semakin pesat juga ikut berdampak dalam mempengaruhi sistem pembayaran yang juga ikut berkembang. Seiring dengan semakin meningkatnya globalisasi ekonomi dunia, kebutuhan masyarakat akan kecepatan, kemudahan dan keamanan transaksi keuangan semakin meningkat. Sehingga diperlukan sistem pembayaran yang cukup handal dan mudah bagi nasabah perbankan. Sistem pembayaran merupakan suatu mekanisme yang mencakup pengaturan yang digunakan untuk penyampaian pembayaran melalui pertukaran nilai antar perorangan, lembaga keuangan baik secara domestik maupun global (Ferry Mulyanto, 2015:19). Perkembangan dalam transaksi jual beli yang tidak lagi terdapat dinding- - 
dinding yang membatasi antara pihak - pihak mengakibatkan alat pembayaran juga menjadi berkembang.

Cryptocurrency merupakan mata uang digital yang menggunakan teknologi kriptografi sebagai keamanan serta sulit untuk dipalsukan dan dimana transaksinya dapat dilakukan atau harus dilakukan dalam jaringan internet (online) untuk setiap transaksi data akan dilakukan penyandian menggunakan algoritma kriptografi tertentu (Ferry Mulyanto, 2015:19). Perbedaan cryptocurrency dari mata uang yang ada yaitu mata uang kripto ini tidak dikeluarkan oleh otoritas pusat, tidak adanya campur tangan atau manipulasi oleh pemerintah. Pada awalnya mata uang kripto ini tidak dipandang sebagai nilai tukar yang bisa mewakili mata uang digital yang ada. Namun karena perkembangannya yang pesat menjadikan mata uang kripto ini segera diketahui oleh banyak orang. Bitcoin yang ditemukan oleh Satoshi Nakamoto pada tanggal 3 Januari 2009 dengan implementasi peer to peer (jaringan penghubung). Kemudian Ethereum (ETH), Bitcoin Cash, Lite Cash, dll. Karena berbentuk mata uang digital, cara pendistribusian cryptocurrency ini diberikan kepada mereka yang melakukan penambangan.

Masalah yang dihadapi adalah bagaimana cryptocurrency dapat dimanfaatkan untuk sistem pembayaran di Indonesia. Tujuan penelitian adalah meninjau penggunaan cryptocurrency sebagai alat pembayaran sehingga dapat digunakan menjadi sebuah sistem pembayaran yang terintegrasi. Penelitian ini akan bermanfaat membantu terlaksananya perpindahan uang secara efisien di masyarakat, sehingga turut meningkatkan kepercayaan masyarakat terhadap rupiah, sehingga secara tidak langsung ikut meningkatkan tingkat kelancaran perekonomian Indonesia. Karena didukung oleh sistem pembayaran yang lebih mudah, aman serta cepat, dan juga tidak lupa akibat hukum apa saja yang ditimbulkan dalam penggunaan cryptocurrency sebagai alat pembayaran di Indonesia.

Dalam artikel ini penulis akan membahas mengenai apakah cryptocurrency dapat menggantikan uang konvensional sebagai alat pembayaran di Indonesia.

\section{B. Metode Penelitian}

Artikel ini termasuk ke dalam jenis penelitian hukum normatif. Sifat penelitian yang digunakan yaitu penelitian preskriptif untuk menghasilkan konsep baru dalam menyelesaikan permasalahan yang dihadapi (Peter Mahmud Marzuki, 2011:35). Pendekatan penelitian yang akan digunakan dalam penelitian ini adalah pendekatan undang-undang (statue approach) dan pendekatan kasus (case approach) (Peter Mahmud Marzuki, 2011 : 133). Jenis data yang akan digunakan penulis dalam penelitian ini adalah data sekunder, yaitu data yang diperoleh melalui pengkajian pustakapustaka yang ada dalam hal ini bahan hukum sekunder adalah jurnal-jurnal, buku-buku dan doktrin dari para ahli mengenai sebuah analisis, Serta Bahan Hukum Primer sebagai bahan hukum yang sifatnya mengikat dan mendasar. Teknik pengumpulan bahan hukum yang akan digunakan dalam penelitian hukum ini adalah studi dokumen atau studi kepustakaan (library research).

\section{Hasil Penelitian dan Pembahasan}

Dalam Undang-undang No. 23 tahun 1999 tentang Bank Indonesia bahwa dalam sistem pembayaran juga mencakup tentang alat pembayaran serta prosedur perbankan sehingga membuat alat pembayaran menjadi komponen penting pada sistem pembayaran, hal ini menjadikan sistem pembayaran perlu alat pembayaran untuk menunjang sistem tersebut tetap perjalan sesuai dengan tata cara serta prosedur yang telah disediakan. Untuk menyatakan alat pembayaran dapat berlaku yaitu memiliki syarat bahwa dapat diterima secara umum atau bersifat acceptability, agar diakui sebagai alat tukar yang umum maka alat pembayaran tersebut harus memiliki nilai dan dijamin keberadaannya oleh pemerintah yang berkuasa.

Memiliki nilai yang stabil juga menjadi syarat penting alat pembayaran, hal ini menjadi sangat penting karena sebagai alat tukar harus memiliki nilai standar di situ peran pemerintah yang berkuasa mengenai nilai alat pembayaran disini yaitu Bank Indonesia. Tertulis didalam Undang- 
undang No. 23 tahun 1999 tentang bank Indonesia bahwa salah satu tugas Bank Indonesia dalam rangka mencapai dan memelihara kestabilan nilai rupiah adalah mengatur dan menjaga kelancaran sistem pembayaran. Hal ini perlu dijaga keseimbangannya agar nilai uang sebagai alat tukar tidak bersifat fluktuatif, maka stabilnya nilai dalam jenis mata uang rupiah harus sesuai dengan mata uang global.

Syarat-syarat yang lain meliputi didalam unsur alat pembayaran adalah:

1. Diterima secara umum (acceptability), sehingga diakui sebagai alat tukar umum suatu benda harus memiliki nilai tinggi atau setidaknya dijamin keberadaannya oleh pemerintah yang berkuasa;

2. Memiliki nilai yang cenderung stabil (stability of value), Nilainya stabil dalam artian nilai yang sekarang sama dengan nilai yang akan datang. Dengan demikian masyarakat percaya bahwa menyimpan uang tidak akan merugikan dinyatakan juga tidak fluktuatif;

3. Ringan dan mudah dibawa (portability), jika melakukan transaksi dalam jumlah yang besar pemilik uang tidak mengalami kesulitan dalam pembayaran;

4. Bahan yang dijadikan uang harus tahan lama (durability);

5. Kualitasnya cenderung sama (uniformity);

6. Jumlahnya dapat memenuhi kebutuhan masyrakat serta tidak mudah dipalsukan (scarcity);

7. Mudah dibagi tanpa mengurangi nilai (divisibility), pada saat transaksi sekecil apapun uang mempunyai pecahan dan nilainya tidak berkurang.

Kaitan antara cryptocurrency dengan penggunaan uang di sini sebagai alat pembayaran dikhususkan sebagai alat tukar (Ole Bjerg : 2015). Jika uang sebagai alat pembayaran sudah berjalan lama hingga sekarang ini, namun bisakah cryptocurrency sebagai alat pembayaran yang sah di Indonesia ditinjau dari kegunaan dasarnya yang sama sebagai alat tukar, kedua jenis alat pembayaran ini tidak dapat disamakan karena memiliki kelebihan serta kekurangan. Uang dan cryptocurrency memiliki nilai atau value, hal ini penting karena untuk menjadi alat pembayaran seperti yang dituliskan dalam Peraturan Bank Indonesia Nomor 17/3/PBI/2015 mengenai mata uang menyebutkan bahwa untuk menjadi mata uang yang berlaku secara umum di masyarakat harus memiliki kestabilan nilai atau value dalam kegunaannya.

Uang dan cryptocurrency ini sudah pasti memiliki perbedaan yang signfikan, dari karakteristik penggunaannya yang sifatnya berbeda dan cara pembuatan atau mendapatkan yang berbeda. Jika uang disebut sebagai mass produced atau diproduksi secara massal oleh satu pihak yang berhak membuat, berbeda dengan cryptocurrency. Mata uang crypto terbuat dari jaringan peer to peer yang kata lainnya merupakan sistem blockchain yang mengikat satu sama lain sehingga membuat sebuah kode-kode yang diakses oleh pihak mining sehingga kode tersebut menjadi angka yang bernilai. Hal ini membuat cryptocurrency untuk mendapatkannya bisa dari mana saja asal ada jaringan yang memiliki blockchain tersebut diakses oleh para mining sehingga sumbernya tidak berasal dari satu pihak, melainkan dari puluhan sampai ratusan pihak pemilik jaringan peer to peer tersebut. Ini yang menjadi signifikan perbedaan uang dengan cryptocurrency dalam hal pembuatan serta cara untuk mendapatkannya (Flamur Bunjaku: 2017).

\begin{tabular}{|c|c|l|l|}
\hline \multicolumn{4}{|c|}{ Perbedaan Uang Konvensional dan Cryptocurrency (mata uang kripto) } \\
\hline No. & \multicolumn{1}{|c|}{ Ditinjau dari } & \multicolumn{1}{|c|}{ Uang Konvensional } & \multicolumn{1}{c|}{ Cryptocurrency } \\
\hline 1. & Produksi & $\begin{array}{l}\text { Bank Indonesia memiliki otoritas } \\
\text { untuk mencetak uang baru melalui } \\
\text { Perusahaan Umum Percetakan } \\
\text { Uang Republik Indonesia } \\
\text { (PERURI). }\end{array}$ & $\begin{array}{l}\text { Mata uang kripto diproduksi dengan } \\
\text { cara enskripsi data dari sistem } \\
\text { jaringan peer to peer. }\end{array}$ \\
\hline 2. & Pendistribusian & $\begin{array}{l}\text { Didistribusikan oleh Bank Indonesia } \\
\text { secara umum. }\end{array}$ & $\begin{array}{l}\text { Oleh pelaku mining yang disebut } \\
\text { sebagai miner. }\end{array}$ \\
\hline
\end{tabular}




\begin{tabular}{|c|l|l|l|}
\hline No. & Ditinjau dari & \multicolumn{1}{|c|}{ Uang Konvensional } & \multicolumn{1}{|c|}{ Cryptocurrency } \\
\hline 3. & Regulasi & $\begin{array}{l}\text { Diatur oleh Bank Indonesia sebagai } \\
\text { otoritas moneter perbankan dan } \\
\text { sistem pembayaran. }\end{array}$ & $\begin{array}{l}\text { Tidak diatur oleh Lembaga atau } \\
\text { pihak apapun. }\end{array}$ \\
\hline 4. & Nilai & $\begin{array}{l}\text { Bersifat stabil sesuai dengan } \\
\text { neraca moneter atau neraca bank } \\
\text { dunia. }\end{array}$ & $\begin{array}{l}\text { Ditentukan berdasarkan penawaran } \\
\text { dan permintaan bersifat fluktuatif. }\end{array}$ \\
\hline 5. & Penggunaan & $\begin{array}{l}\text { Dapatdigunakan untuk bertransaksi } \\
\text { sebagai alat pembayaran yang } \\
\text { umum, bisa dipakai sehari-hari } \\
\text { secara konvensional. }\end{array}$ & $\begin{array}{l}\text { Membutuhkan adanya jaringan } \\
\text { internet untuk dapat menggunakan, } \\
\text { transaksi bisa dilakukan selama } \\
\text { ada jaringan internet. }\end{array}$ \\
\hline 6. & Akses/Fungsi & $\begin{array}{l}\text { Sebagai alat tukar atau alat } \\
\text { pembayaran, dapat disimpan/ } \\
\text { ditabung sebagai alat timbun } \\
\text { kekayaan, dan dapat digunakan } \\
\text { untuk pembayar hutang. }\end{array}$ & $\begin{array}{l}\text { Sebagai alat untuk menyimpan } \\
\text { kekayaan, membeli barang secara } \\
\text { online, dan juga dapat menjadi alat } \\
\text { pembayaran hutang secara online. }\end{array}$ \\
\hline
\end{tabular}

Teknologi bidang fintech menghasilkan inovasi - inovasi baru dalam bidang sistem pembayaran salah satunya Electronic Money, Electronic Money atau biasa disebut E-Money disebut sebagai alternatif alat pembayaran non-tunai yang tidak hanya berbentuk kartu tetapi juga dalam bentuk seperti tersimpan dalam jenis aplikasi dalam smartphone. Penyedia jasa layananya tidak hanya dari pihak bank tetapi meliputi Lembaga selain Bank yaitu perusahaan keuangan, perusahan transportasi publik serta perusahaan provider telekomunikasi juga ikut andil dalam jasa layanan sistem pembayaran ini. Lembaga dan perusahaan ini dapat membuat aplikasi dengan jenis electronic money karena pihak dari mereka sendiri yang dapat mengatur transaksi didalam aplikasi yang telah dibuat, memiliki andil alih dalam pengawasannya (Nurfia Oktaviani Syamsiah : 2017).

Ketentuan yang mengatur tentang uang elektronik atau E-Money ada pada Peraturan Bank Indonesia Nomor 11/12/PBI/2009 Tentang Uang Elektronik (Electronic Money) yang menurut ketentuan peraturan ini uang elektronik pada hakikatnya sebagai pengganti uang tunai, penerbitannya atas dasar nilai uang yang disetor yang saldonya tersimpan pada suatu media server atau chip. Uang elektronik tersebut dapat digunakan sebagai alat pembayaran pada merchant-merchant retail tertentu yang mengadakan kerjasama dengan penerbit uang elektronik. Penggunaannya dalam transaksi juga mudah sehingga untuk melakukan pembayaran cukup dengan melakukan scan pada barcode yang ada pada merchant tersebut. Dinyatakan bahwa uang elektronik merupakan instrument pembayaran tanpa uang fisik yang memiliki karakteristik sama dengan uang tunai dengan fungsi yang sama yaitu sebagai alat pembayaran atau alat tukar juga diawasi oleh Lembaga atau perusahaan yang bersangkutan.

\begin{tabular}{|c|c|l|l|}
\hline \multicolumn{3}{|c|}{ Perbedaan Uang Elektronik dan Cryptocurrency } \\
\hline No. & Ditinjau Dari & \multicolumn{1}{|c|}{ Uang Elektronik } & \multicolumn{1}{c|}{ Cryptocurrency } \\
\hline 1. & Penyelenggara & $\begin{array}{l}\text { Entitas berupa Bank atau Lembaga } \\
\text { Selain Bank (LSB) yang bentuknya } \\
\text { Perseroan Terbatas. }\end{array}$ & $\begin{array}{l}\text { Tidak ada penyelenggara yang } \\
\text { pasti, hanya antara jaringan block } \\
\text { chain dengan pelaku disebut miner } \\
\text { atau penambang. }\end{array}$ \\
\hline 2. & Produksi & $\begin{array}{l}\text { Diterbitkan oleh entitas terkait yaitu } \\
\text { Bank atau LSB ke dalam beberapa } \\
\text { produk, dijamin oleh Otoritas Jasa } \\
\text { Keuangan (OJK) }\end{array}$ & $\begin{array}{l}\text { Perhitungan algoritma melalui data } \\
\text { enskripsi, untuk mendapatkannya } \\
\text { bisa membeli di bursa virtual } \\
\text { currency atau dapat menambang } \\
\text { (mining) }\end{array}$ \\
\hline
\end{tabular}




\begin{tabular}{|c|c|c|c|}
\hline 3. & Sistem & $\begin{array}{l}\text { Berbasis Server dan berbasis Chip } \\
\text { RFID. Pencatatan Transaksinya } \\
\text { terpusat pada satu server. }\end{array}$ & $\begin{array}{l}\text { Jaringan server peer to peer atau } \\
\text { disebut Block Chain. Pencatatan } \\
\text { transaksinya terdesentralisasi oleh } \\
\text { jaringan Block Chain. }\end{array}$ \\
\hline 4. & Nilai & $\begin{array}{l}\text { Sama dengan uang konvensional } \\
\text { pada tiap masing-masing negara. } \\
\text { Bisa dimanipulasi nilainya }\end{array}$ & $\begin{array}{l}\text { Nilainya tidak dapat dimanipulasi, } \\
\text { ditentukan oleh permintaan serta } \\
\text { penawaran. }\end{array}$ \\
\hline 5. & Keamanan & $\begin{array}{l}\text { Terpusat pada satu server } \\
\text { kemungkinan untuk pencurian data } \\
\text { lebih tinggi jika diretas langsung ke } \\
\text { server pusat. }\end{array}$ & $\begin{array}{l}\text { Karena jaringan server-nya } \\
\text { berbentuk Block Chain serta } \\
\text { enkripsi datanya yang sulit untuk } \\
\text { dimanipulasi maka sangat susah } \\
\text { untuk pencurian data. }\end{array}$ \\
\hline 6. & $\begin{array}{l}\text { Jangakuan } \\
\text { Transaksi }\end{array}$ & $\begin{array}{l}\text { Terbatas, hanya melalui merchant } \\
\text { atau melalui mesin yang disediakan } \\
\text { oleh jasa pelayanan. Nilai Tran- } \\
\text { saksinya dimulai dari paling kecil } \\
\text { serta penggunaannya bersifat } \\
\text { umum. }\end{array}$ & $\begin{array}{l}\text { Lebih Luas, dapat digunakan di } \\
\text { beberapa negara dengan fasilitas } \\
\text { belanja online antar negara. Nilai } \\
\text { Transaksinya cenderung tinggi } \\
\text { serta penggunaannya bersifat lebih } \\
\text { khusus. }\end{array}$ \\
\hline 7. & Logo & $\begin{array}{l}\text { Logo E-Money yang dimiliki oleh } \\
\text { Bank Mandiri } \\
\text { Logo Go-Pay yang dimiliki oleh } \\
\text { Gojek Indonesia }\end{array}$ & $\begin{array}{l}\text { Logo Bitcoin, salah satu jenis } \\
\text { Cryptocurrency paling banyak } \\
\text { diminati di dunia } \\
\text { Logo Ethereum, Jenis } \\
\text { Cryptocurrency setelah Bitcoin }\end{array}$ \\
\hline
\end{tabular}

Pada kenyataan yang terjadi di Indonesia, cryptocurrency tidak dapat digunakan di Indonesia untuk menjadi pengganti mata uang yang telah ada, mata uang konvensional merupakan mata uang yang terintegrasi dengan Bank Indonesia sehingga perputaran atau peredarannya masih dapat dipantau sementara yang menjadi riskan dalam penggunaan cryptocurrency dalam alat pembayaran di Indonesia yaitu peredarannya yang tidak terlihat karena tidak terpusat atau dalam hal ini disebut jaringan peer-to-peer yang penggunaannya terdesentralisasi tanpa server atau server pusat (Isak Andri Olafsson : 2014).

Di Indonesia, Bank Indonesia menjadi satu-satunya otoritas moneter dalam sistem pembayaran dengan menggunakan uang sehingga pihak Bank Indonesia dapat menentukan alat pembayaran jenis apa saja yang berlaku di Indonesia. Dalam Undang - Undang No. 7 tahun 2011 tentang Mata Uang pasal 11 menjelaskan bahwa Bank Indonesia merupakan satu-satunya Lembaga yang berwenang melakukan pengeluaran, pengedaran dan/atau pencabutan dan penarikan rupiah. Dinyatakan jelas di pasal tersebut hanya Bank Indonesialah yang berhak melakukan pengelolaan rupiah atau mata uang yang belaku di Indonesia. 
Dalam pasal 12 Undang - Undang No. 7 tahun 2011 tentang Mata Uang juga menjelaskan bahwa Bank Indonesia juga ikut dalam pengaturan pengamanan, hal ini meliputi perencanaan serta penentuan jumlah rupiah atau uang yang dicetak dilakukan oleh Bank Indonesia yang berkoordinasi dengan pemerintah dan juga Bank Indonesia berlaku sebagai penyedia jumlah Rupiah yang beredar. Pentingnya hal ini dikarenakan setiap produksi mata uang Rupiah harus memiliki Nomor Seri pada tiap uang kertasnya, maksud dari hal ini agar uang tersebut dapat dilacak kebenarannya atau keasliannya juga dapat diketahui dari pihak bank swasta mana yang sedang menyimpan uang dengan nomor seri tersebut. Itu menjadikan Bank Indonesia pengawas atas peredaran uang yang telah mereka buat dan diedarkan sehingga tanggung jawab Bank Indonesia tidak berhenti ketika uang tersebut sudah diedarkan. Itu salah satu penyebab kenapa Cryptocurrency tidak dapat menjadi alat pembayaran yang sah karena tidak dapat dilacak keberadaannya karena sifatnya yang harus selalu menggunakan jaringan internet menjadi susah untuk dilacak. Cryptocurrency terus muncul sehingga tidak dapat dilacak satu-persatu keberadaannya dan kecepatan dalam mendapatkan enskripsi data sehingga sangat sulit untuk dilacak.

Realistisnya, Cryptocurrency bisa digunakan tetapi karena nilai dari cryptocurrency yang relatif tidak stabil (Fluktuatif)(William J. Luther, 2014:6) daripada mata uang yang sudah beredar di Indonesia ini yaitu rupiah sudah menjadi sisi negatif dari cryptocurrency. Pola alat pembayaran yang sudah ada dari jaman barter atau tukar menukar barang yaitu alat pembayaran yang sah dapat digunakan untuk barang yang nilainya kecil sampai ke nilai yang besar. Itulah cryptocurrency akan sulit berkembang di Indonesia karena tidak efektifnya kegunaan dalam sehari-hari

\section{Simpulan}

Uang sebagai alat pembayaran atau alat tukar harus memiliki beberapa syarat unsur mengenai mata uang yang terkait, cryptocurrency untuk menjadi sistem transaksi keuangan yang baru di Indonesia merupakan teknologi yang relatif baru dan perlu dikaji lebih lanjut. Perlu banyak aspek dalam perbankan serta dunia fintech yang perlu dipelajari untuk dapat menggunakan cryptocurrency sebagai alat pembayaran atau alat tukar yang baru. Dunia perbankan memiliki standar protokol dan parameter yang rumit dalam memberikan standarisasi sistem pembayaran, cryptocurrency sejauh ini belum memiliki standarisasi yang jelas karena belum adanya pihak otoritas yang berwenang dalam menghadapi masalah penggunaan cryptocurrency di Indonesia penanggung jawab penggunaan hanya dimiliki oleh para penggunanya sendiri terkait bahwa sebagai alat pembayaran, cryptocurrency menjadi alat bayar langsung antara dua pihak tanpa perlu perantara atau tidak ada campur tangan pihak ketiga sehingga dalam monitor pergerakan serta peredarannya akan lebih sulit daripada uang konvensional yang sudah beredar.

Cryptocurrency bisa dinyatakan sebagai solusi sebagai sistem pembayaran di tingkat lain, tingkatnya angka permintaan dari jenis mata uang kripto ini tidak sebanding dengan suplai yang ada. Hal yang akan terjadi kemudian cryptocurrency tidak menjadi alat pembayaran sehari-hari namun menjadi alat pembayaran atau alat tukar yang akan lebih spesifik pada tingkatan tertentu. Untuk sekarang cryptocurrency hanya bisa menjadi alat investasi yang putarannya hanya dibeli lalu dijual, sulit bila cryptocurrency disandingkan langsung dengan uang untuk kegunaan alat pembayaran sehari hari.

\section{E. Saran}

Perlu adanya koordinasi mengenai penggunaan cryptocurrency sebagai alat pembayaran yang sah di Indonesia, seperti halnya otoritas yang mengatur keluar masuknya cryptocurrency agar dapat melacak peredaran serta penggunaannya. Regulator juga perlu disematkan agar nilai tukarnya tidak sewaktu - waktu tinggi atau rendah (fluktuatif) sehingga memiliki nilai rata - rata sebagai alat tukar dengan batasan yang sesuai dengan peraturan yang telah dibuat mengenai uang. Pengkajian lebih lanjut mengenai unsur uang dalam cryptocurrency untuk alat pembayaran atau alat tukar juga diperlukan, unsur diperlukan dengan upaya jika benar - benar digunakan tidak 
adanya perbedaan dengan mata uang konvensional sehingga disebut sebagai alternatif uang konvensional dengan bentuk digital. Hal ini diupayakan agar masyarakat dan khalayak umum lebih dapat menerima pengertian yang benar terhadap cryptocurrency dan dapat mengambil kesimpulan yang positif maupun negatif dari bayangan akibat penggunaannya.

\section{F. Daftar Pustaka}

Peter Mahmud Marzuki. 2011. Penelitian Hukum. Jakarta: Prenada Media Group

Isak Andri Olafsson. 2014. "Is Bitcoin money?" An Analysis from the Austrian School of economic Thought. Austria : University of Islandia

Fery Mulyanto. 2015. "Pemanfaatan Cryptocurrency sebagai Penerapan Mata Uang Rupiah ke dalam Bentuk Digital Menggunakan Teknologi Bitcoin". Indonesian Journal on Networking and Security Vol. 4 No. 4. Bandung : Universitas Pasundan Bandung

Flamur Bunjaku \& Olivera Gjorgieva-Trajkovska. 2018. "Cryptocurrencies - Advantages and Disadvantages". Journal of Economics Issue 1 Vol. 2. Macedonia : University Goce Delcev Stip Journal

Nurfia Oktaviani Syamsiah. 2017. "Kajian Atas Cryptocurrency sebagai Alat Pembayaran di Indonesia". IJNS Vol. 6 No. 1. Jakarta : BSI Jakarta

Ole Bjerg. 2015. "How is Bitcoin Money?". An Article from the Coppenhagen Business School. Coppenhagen: Coppenhagen Business School

William J. Luther and Lawrence H. White. 2014. "Can Bitcoin Become a Major Currency?". Department of Economics Working Paper No. 14-17. Virginia : George Mason University

Peraturan Bank Indonesia Nomor 18/40/PBI/2016 tentang Penyelenggaraan Pemrosesan Transaksi Pembayaran

Undang-Undang Republik Indonesia Nomor 7 Tahun 2011 tentang Mata Uang

Undang-Undang Nomor 23 Tahun 1999 tentang Bank Indonesia 